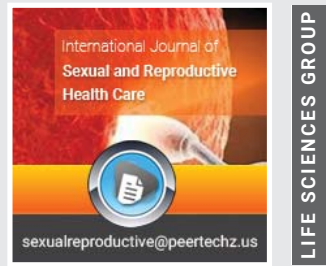

\title{
Etiological factors and
}

\section{comorbidities associated with}

the "Gender Dysphoria":

\section{Definition, clinical contexts,}

\section{clinical treatments}

\section{Giulio Perrotta*}

Psychologist sp.ing in Strategic Psychotherapy, Forensic Criminologist, Legal Advisor sp.ed SSPL,

Researcher, Essayist, Istituto per lo studio delle psicoterapie - ISP, Via San Martino della Battaglia $\mathrm{n}$.

31, 00185, Rome, Italy

Received: 17 December, 2020

Accepted: 05 March, 2021

Published: 06 March, 2021

*Corresponding author: Dr. Giulio Perrotta, Psychologist sp.ing in Strategic Psychotherapy, Forensic Criminologist, Legal Advisor sp.ed SSPL, Researcher, Essayist, Istituto per lo studio delle psicoterapie - ISP, Via San Martino della Battaglia n. 31, 00185, Rome, Italy,

E-mail:info@giulioperrotta.com

Keywords: Gender Dysphoria; PICl-1

https://www.peertechzpublications.com

\section{Check for updates}

\section{Abstract}

Purpose: Starting from the concept of "gender dysphoria", this research aims to find out if there is a correlation between GD and personality disorders.

Methods: Having selected the population sample of 255 subjects, having the requirements of age between 18 and 72 years and a declaration of perceived transsexuality, in transition or final, and domiciled in Italy for at least 5 years regardless of citizenship and nationality, it was decided to proceed with the clinical interview and administration of the PICI-1 (TA). It was considered unnecessary to administer the MMPI-II, as a previous study by the same author has demonstrated the effectiveness and efficiency of the test.

Results: Using the PICl-1, the following data emerged during the clinical interview: 1) The female population sample ( $\mathrm{F} \rightarrow \mathrm{M}$ ) is smaller and more difficult to find; moreover, the perception of one's transsexuality, as well as the desire to change one's gender occurs in 100\% (40/40) of cases before the age of 36. 2) The sample of the male population $(\mathrm{M} \rightarrow \mathrm{F})$ is more consistent and reports $84.13 \%(179 / 211)$ perceived or acted on the change before the age of 36 . 3 ) The total population sample of 255 subjects had $97.5 \%$ (250/255) at least 5 dysfunctional personality traits among the disorders of PICl-1 cluster B (TA), i.e. borderline, histrionic, narcissistic, antisocial, sadistic and masochistic, while 56.55\% (145/255) had at least 3 dysfunctional traits among the disorders of PICl-1 cluster A (TA), i.e. anxious, obsessive, depressed, phobic and somatic.

Conclusions: The research carried out gave further evidence that $97.5 \%$ (250/255) at least 5 dysfunctional personality traits among the disorders of PICl-1 cluster B (TA), i.e. borderline, histrionic, narcissistic, antisocial, sadistic and masochistic, while $56.55 \%(145 / 255)$ had at least 3 dysfunctional traits among the disorders of PICl- 1 cluster A (TA), i.e. anxious, obsessive, depressed, phobic and somatic. However, in the future, studies are expected that subject children between the ages of 2 and 6 who already have the first dysphoric symptomatology to MRI and electroencephalogram every six months, following them up to adulthood, to understand if the anomalies represented are already present or not, and from that point begin to reason about the subject's sexual evolution. Furthermore, a series of researches focused on a relevant and significant statistical sample is hoped, to be able to reconstruct the genesis of dysphoria and understand the exact incidence of serious psychopathological forms (including indirectly related disorders, such as paraphilias and different orientations sexual) and whether these are etiological factors, contributing factors or consequences of the primary condition, also and above all concerning the neurobiological and endocrinological clinical profiles. 


\section{Contents of the manuscript}

\section{Definition and clinical contexts}

"Gender dysphoria" is the new definition of "gender identity disorder" contained in previous versions of DSM-V, the diagnostic and statistical manual of mental disorders, intended as a strong and persistent identification with the opposite sex, associated with anxiety, depression, irritability, malaise, a sense of non-belonging and an intense desire to live as a gender other than the sex assigned to birth. People with gender dysphoria feel victims of a biological accident and therefore live their condition as if they were cruelly imprisoned in a body incompatible with their subjective gender identity. "Sex" therefore refers to a person's biological and physiological properties, while "gender" refers to the personal psychological identification of the binary gender for men and women, to the social roles assigned and to social and cultural learning processes. On this assumption, gender dysphoria is independent of sexual orientation and should not be confused with it: transsexual women and men can have any sexual and sentimental orientation, for example they can be heterosexual, homosexual, or bisexual. The result of an inconsistency between the psychological gender and biological sex determines in the transsexual individual a continuous search for similarity to the preferred sex and the strong identification with the opposite gender in combination with the prevalence, in most cultures, of a system of binary gender, as well as poor social acceptance, causes serious psychological stress in transsexuals. Psychiatric disorders appear high in this patient population when compared with the general population, with a spike in anxiety and mood disorders. However, transsexualism, according to the modern $\mathrm{DSM}-\mathrm{V}$, is not directly associated with psychiatric disorders, but it is assumed that these problems are the result of strong stressful social experiences and therefore transsexuals who suffer from their condition can also receive the diagnosis of "Gender dysphoria". Being transsexual is not an automatic condition for assigning a dysphoric diagnosis [1].

\section{Differential diagnosis and clinical treatments}

In the past, drawing on psychoanalytic theories, it was believed that gender dysphoria was associated with personality disorders, and that it was often the consequence of such serious disorders, due to a dysfunctional attachment [2], psychophysical violence in childhood $[1,3]$ and a geneticneurobiological predisposition. Therefore, personality disorders were considered an etiological factor and not a consequence of the disorder itself $[1,4]$

In particular, Sperber [5] stated that colors such as showing a Dysphoria of Gender presented a Borderline type personality, while - more recently - Chiland [6] considered transsexualism as a Narcissistic Disorder with a profound disturbance of selfconstitution. Hoening, et al. [7], however claimed that $70 \%$ of transsexuals showed a psychiatric diagnosis, although only $13 \%$ were frankly psychotic and Meyer [8] and Steiner [9] found Narcissistic, Borderline and Antisocial Personalities, with some schizoid traits, or structured disorders such as depression, anxiety, suicidal tendencies, and homicidal impulses. Gosselin and Wilson [10] also found evidence of introversion and high neuroticism compared to males without dysphoria. Dèttore [11] notes, however, that the tendency to show serious psychopathological forms is greater in transsexual males than women, despite contrary literature, signed by Lothstein $[12,13]$. Bockting and Coleman [14]-which detected important phobic, obsessive, anxious, depressive and dysmorphic traits [15]- and Hartmann [16]-which revealed important psychopathological aspects and a considerable narcissistic dysregulation.

Lev [17], distancing himself from this type of literature, argues that research on gender variance and transsexuals was conducted on people who go to specialized clinical centers, and therefore they were more suffering subjects and therefore more likely to have serious psychopathologies, connected or secondary to their primary condition. The author also maintains that easy diagnostic labeling speeds up the pathologization process of dysphoria which instead must simply be considered a normal healthy variant of the expression of human identity, without any pathological component.

This position, although extreme and disavowed by neurobiological results [1], is supported in part by a more indulgent literature on the transsexual phenomenon, which therefore adheres to a milder interpretation of clinical morbidity. Starting from the second half of the last century, Holtzman, et al. [18] argued that subjects with dysphoria were generally well organized and with intellectually adequate thought processes. Bentler and Prince did not observe important differences on the neurotic or psychotic scales between transsexuals and control subjects, while Cole et al., more recently, had shown that less than $10 \%$ of their statistical sample (approximately 400 people) showed previous mental disorders. Carroll [19], Menichini [20], Haraldsen [21], Miach [22], Cohen-Kettins and van Goozen $[23,24]$ stated that transgender people did not necessarily show higher mental disorder levels than the nonclinical population [25]; however, the statistical data in many of these searches were not significant, effectively invalidating the result obtained. Another figure that appears truly relevant is offered by the research by Courvant and Cooke-Daniels [26], which connect the psychiatric symptomatology of subjects with dysphoria with the high psycho-social stress to which they are subjected (with strong prejudice and public condemnation) and with the results of one or more post-traumatic stress events in childhood, the consequence of physical and / or psychological sexual violence. [27-30] For Mathy and Marshall, suicidal risk [31] is extremely frequent [32], as well as eating disorders, for Hepp [33] and drug abuse and spirits, for Day [34].

On the basis of these results, the writer used the PICI-1 (TA) [35-37], during the clinical interview, in a population sample of 255 subjects, having the requirements of age between 18 and 72 and a declaration of perceived transsexuality, in transition or definitive, and domiciled in Italy for at least 5 years regardless of citizenship and nationality, obtaining the following results:

\begin{tabular}{|c|c|c|c|c|c|c|c|c|c|}
\hline & \multicolumn{2}{|c|}{$\begin{array}{c}\text { Perceived } \\
\text { Transsexualism } \\
\text { (cluster A) }\end{array}$} & \multicolumn{2}{c|}{$\begin{array}{c}\text { Transsexualism in } \\
\text { transition } \\
\text { (cluster B) }\end{array}$} & \multicolumn{3}{c|}{$\begin{array}{c}\text { Definitive } \\
\text { Transsexualism } \\
\text { (cluster C) }\end{array}$} \\
\hline AGE & $\mathbf{1 8 - 3 6}$ & $\mathbf{3 7 - 5 4}$ & $\mathbf{5 5 - 7 2}$ & $\mathbf{1 8 - 3 6}$ & $\mathbf{3 7 - 5 4}$ & $\mathbf{5 5 - 7 2}$ & $\mathbf{1 8 - 3 6}$ & $\mathbf{3 7 - 5 4}$ & $\mathbf{5 5 - 7 2}$ \\
\hline M $>$ F & 21 & 6 & 0 & 86 & 16 & 0 & 72 & 10 & 0 \\
\hline F $>$ M & 12 & 0 & 0 & 16 & 4 & 0 & 12 & 0 & 0 \\
\hline
\end{tabular}


The selected setting, taking into account the protracted pandemic period (already in progress since the beginning of the present research), is the online platform via Skype and Videocall Whatsapp, both for the clinical interview and for the administration.

All participants were guaranteed anonymity.

The present research work was carried out from March 2020 to December 2020.

Using the PICI-1, unlike the MMPI-II, the following data emerged during the clinical interview:

1) The female population sample $(F \rightarrow M)$ is smaller and more difficult to find; moreover, the perception of one's transsexuality, as well as the desire to change one's gender occurs in $100 \%(40 / 40)$ of cases before the age of 36 .

2) The sample of the male population $(M \rightarrow F)$ is more consistent and reports $84.13 \%(179 / 211)$ perceived or acted on the change before the age of 36 .

3) The total population sample of 255 subjects had $97.5 \%$ (250/255) at least 5 dysfunctional personality traits among the disorders of PICI-1 cluster B (TA), i.e. borderline, histrionic, narcissistic, antisocial, sadistic and masochistic, while 56.55\% (145/255) had at least 3 dysfunctional traits among the disorders of PICI-1 cluster A (TA), i.e. anxious, obsessive, depressed, phobic and somatic.

The main limitations of the research are two:

a) The use of a population sample that is not sufficiently representative; however, the data obtained are very interesting and deserve to be further investigated with a larger population sample.

b) The PICI-1 is not yet standardised psychometric instruments but are proposed, despite the excellent results obtained and already published in international scientific journals [35-37].

This research has no financial backer and does not present any conflicts of interest.

\section{Conclusions}

Although the discomfort regarding one's gender identity can take various forms and different intensities, the etiology of Gender Dysphoria is still uncertain and the many theories on the subject highlight its multifactorial: genetics and neurobiology $[1,38,39]$, hormonal $[1,40,41]$, psychological $[2,3,42]$.

It is therefore clear that, from the studies conducted so far, there are substantial elements to be able to assume that the neuroanatomophysiology of a dysphoric is different from a non-dysphoric subject, but the studies have not yet clarified if it is these differences that cause the dysphoric condition or if the dysphoric condition shapes the anatomy and physiology of the brain by inducing the changes. It is logical and consequential to think, however, that the first solution is the most acceptable, and therefore certain anatomical-physiological alterations cause the subject to perceive his identity status in a dysphoric way $[1,43]$.

In the future, studies are expected that subject children between the ages of 2 and 6 who already have the first dysphoric symptomatology to MRI and electroencephalogram every six months, following them up to adulthood, to understand if the anomalies represented are already present or not, and from that point begin to reason about the subject's sexual evolution. Furthermore, a series of researches focused on a relevant and significant statistical sample is hoped, to be able to reconstruct the genesis of dysphoria and understand the exact incidence of serious psychopathological forms (including indirectly related disorders, such as paraphilias and different orientations sexual) [44-48] and whether these are etiological factors, contributing factors or consequences of the primary condition, also and above all concerning the neurobiological and endocrinological clinical profiles.

Despite the full desire to derubricate transsexualism, by the scientific community, the author of this work is strongly skeptical, taking into account the neurobiological results published so far, like homosexuality and bisexuality, and clinical results regarding comorbidity profiles with depressive [49], anxious [50], phobic, obsessive [51], post-traumatic [52], food [53], psychotic [54,55] and personality disorders (with a higher incidence on borderline disorder [56], narcissistic and histrionic) [38,57]. A very controversial and not statistically relevant and significant case was recorded in 2014, in which the patient appears to have undergone a trend conversion, from dysphoric to heterosexual male, following an epileptic state [39]. This circumstance seems to reinforce the neurobiological and endocrinological hypothesis of dysphoria, as one of the primary causes [58-60].

The research carried out, albeit with an unrepresentative sample, gave further evidence that $97.5 \%(250 / 255)$ at least 5 dysfunctional personality traits among the disorders of PICI-1 cluster B (TA), i.e. borderline, histrionic, narcissistic, antisocial, sadistic and masochistic, while 56.55\% (145/255) had at least 3 dysfunctional traits among the disorders of PICI-1 cluster A (TA), i.e. anxious, obsessive, depressed, phobic and somatic.

\section{References}

1. Perrotta G (2020) Gender dysphoria: definitions, classifications, neurobiological profiles, and clinical treatments. Int J Sex Reprod Health Care 3: 042-050. Link: https://bit.ly/3eaVJYd

2. Perrotta G (2020) Dysfunctional attachment and psychopathological outcomes in childhood and adulthood. Open J Trauma 4: 012-021. Link: http://bit.ly/3bhnXPg

3. Piegza M, Leksowska A, Pudlo R, Badura-Brzoza K, Matysiakiewicz J, et al (2014) Gender Identity Disorders or Andromimetic Behaviour in a Victim of Incest: A Case Study. Psychiatr Pol 48: 135-144. Link: http://bit.ly/3blaEgN

4. Perrotta G (2019) Psicologia dinamica, Luxco ed, 1th.

5. Sperber MA (1973) The 'as if' personality and transvestism. Psychoanalytic Review 60: 605-612. 
6. Chiland C (2000) The psychoanalyst and transsexual patient. Int J Psychoana 81: 21-35. Link: http://bit.ly/3eaVSLf

7. Hoening J, Kenna JC, Youd A (1971) Surgical treatment for transsexualism. Acta Psychiatr Scand 47: 106-136. Link: http://bit.ly/3c8wmUx

8. Meyer JK (1974) Clinical variants among applicants for sex reassignment Arch Sex Behav 3: 527-558. Link: http://bit.ly/3uZeiVt

9. Steiner BW (1985) Gender dysphoria: Development, research, management New York: Plenum Press. Link: http://bit.ly/38fcWMi

10. Gosselin C, Wilson G (1980) Sexual variations. New York: Simon and Schuster

\section{Dettore D (2005) II Disturbo dell'Identità di Genere, McGraw-Hill, Milano.}

12. Lothstein LM (1983) Femele-to-male transsexualism: Historical, clinical, and teoric issue. Boston: Routledge and Kegan Paul.

13. Lothstein LM (1984) Psychologic testin with transsexuals: A 30-years review. J Pers Assess 48: 500-507. Link: http://bit.ly/3ro3jTk

14. Bockting WO, Coleman E (1992) A comprehensive approach to the treatment of gender dysphoria. In W. O. Bockting and E. Coleman (Eds.), Gender dysphoria: Interdisciplinary approaches in clinical management. Binghamton, NY: The Haworth Press 131-155. Link: https://bit.ly/3rmsENf

15. Perrotta G (2020) The concept of altered perception in "body dysmorphic disorder": the subtle border between the abuse of selfies in social networks and cosmetic surgery, between socially accepted dysfunctionality and the pathological condition. J Neurol Neurol Sci Disord 6: 001-007. Link: http://bit.ly/3uWvlHv

16. Hartmann U, Becker H, Rueffen-Hesse C (1997) Self and gender: Narcissistic pathology and personality factors in gender dysphoric patient. Preliminary results og a prospective study. International Journal of Transgenderism.

17. Lev Al (2004) Transgender emergence. New York-London-Oxford: The Haworth Clinical Practice Press. Link: https://bit.ly/3rkAWVY

18. Holtzman WH, Thorpe JS, Swartz JD, Herron EW (1961) Inkblot perception and personality. Austin, TX: University of Texas Press. Link: http://bit.ly/3c7Mm92

19. Schaefer LC, Wheeler CC, Futterweit W (1995) Gender identity disorders (transsexualism). In G. O. Gabbard (Ed.), Treatment of psychiatric disorders Washington, DC: American Psychiatric Association.

20. Menichini U, Rasore E, Infante G, Moscato F, Giusti M (1998) II problema dell'identità di genere: una casistica clinica. Medicina Psicosomatica 43: 255270 .

21. Haraldsen IR, Dahl AA (2000) Symptom profile of gender dysphoric patients of transsexual type compared to petients with personality disorders and healthy adults. Acta Psychiatr Scand 102: 276-281. Link: http://bit.ly/38a5cLO

22. Miach PP, Berah EF, Butcher JN, Rouse S (2000) Utility of MMPI-2 in assessing gender dysphoric patient. J Pers Assess 75: 268-279. Link: http://bit.ly/2OqGdNe

23. Cohen-Kettenis PT, Van Goozen SHM (1997) Sex reassignment of adolescent transsexuals: A follow-up study. J Am Acad Child Adolesc Psychiatry 36: 263271. Link: http://bit.ly/3sQ8bAF

24. Cohen-Kettenis PT, Van Goozen SHM (2002) Adolescents who are eligible for sex reassignment surgety. Parental reports of emozional and behavioural problems. Clinical Psychology and Psychiatry 7: 412-422. Link: http://bit.ly/3rfNCgK

25. Brown GR (1990) A review of clinical approaches to gender dysphoria. J Clin Psychiatry 51: 57-64. Link: http://bit.ly/3sOVRAQ

26. Courvant D, Cook-Daniels L (2000) Trans and Intersex Survivors of Domestic Violence: Defining Terms, Barriers and Responsibilities. National Coalition Against Domestic Violence. Link: https://bit.ly/3ef6I2S
27. Bradley SJ, Zucker KJ (1990) Gender identity disorder and psychosexua problems in children and adolescents. Can J Psychiatry 35: 477-486. Link: http://bit.ly/3bWtcTq

28. Cohen-Kettenis P, Owen A, Kaiser V, Bradley S, Zucker K (2003) Demographic characteristics, social competence, and behaviour problems in children with gender identity disorder: a cross-national, cross-clinic comparative analysis. $J$ Abnorm Child Psychol 31: 41-53. Link: http://bit.ly/3e65ne0

29. Cohen-Kettenis PY, Pfäfflin F (2003) Transgenderism and intersexuality in childhood and adolescence: Making choises, Sage Publication, Thousand Oaks 46. Link: http://bit.ly/3rjwkPV

30. Simonelli C, Rossi R, Petruccelli I, Tripodi F (2006) Identità di genere e sviluppo sessuo-affettivo: fattori di rischio e percorsi atipici nell'infanzia e nella preadolescenza. Quale Psicologia (ISP) 28. Link: http://bit.ly/30fpMpp

31. Perrotta G (2020) Suicidal risk: definition, contexts, differential diagnosis, neural correlates and clinical strategies. J Neuroscience Neurological Surgery 6: 114. Link: https://bit.ly/3hUtVaF

32. Marshall E, Claes L, Bouman WP, Witcomb GL, Arcelus J (2016) Non-suicida Self-Injury and Suicidality in Trans People: A Systematic Review of the Literature. In Int Rev Psychiatry 28: 58-69. Link: http://bit.ly/3rl8XW4

33. Hepp U, Milos G (1990) Gender identity disorder and eating disorders International Journal of Eating Disorders 32:: 473-478.

34. Day JK, Fish JN, Perez-Brumer A, Hatzenbuehler ML, Russell ST (2017) Transgender Youth Substance Use Disparities: Results From a PopulationBased Sample. In J Adolesc Health 61: 729-735. Link: http://bit.ly/3rofbV8

35. Perrotta G (2020) Perrotta Integrative Clinical Interview. LK ed., I ed., pag 270 formato A5.

36. Perrotta G (2020) The structural and functional concepts of personality: The new Integrative Psychodynamic Model (IPM), the new Psychodiagnostic Investigation Model (PIM) and the two clinical interviews for the analysis of personality disorders (Perrotta Integrative Clinical Interview or PICI). Link: https://bit.ly/35bcpts

37. Perrotta G (2020) First revision of the Psychodiagnostic Investigation Model (PIM-1R) and elaboration proposal of a clinical interview for the analysis of personality disorders (Perrotta Integrative Clinical Interview or PICl-1) for adults, teenagers and children. Psychiatry Peertechz. Link: https://bit.ly/2MQe3dY

38. Rajkumar RP (2014) Gender Identity Disorder and Schizophrenia: Neurodevelopmental Disorders With Common Causal Mechanisms? Schizophr Res Treatment 2014: 463757. Link: http://bit.ly/3ed61XS

39. Parkinson J (2015) Gender Dysphoria "Cured" by Status Epilepticus. Australas Psychiatry 23: 166-168. Link: http://bit.ly/3c0FiLu

40. Motta G, Crespi C, Mineccia V, Brustio PR, Manieri C, et al. (2018) Does Testosterone Treatment Increase Anger Expression in a Population of Transgender Men? In J Sex Med 15: 94-101. Link: http://bit.ly/3ecLNNQ

41. Turan Ş, Poyraz CA, Öcek Baş T, Kani AS, Duran A, et al. (2015) Affective Temperaments in Subjects With Female-To-Male Gender Dysphoria. In J Affect Disord 176: 61-64. Link: http://bit.ly/3sUSHeK

42. Perrotta G (2020) Psychological trauma: definition, clinical contexts, neural correlations and therapeutic approaches. Curr Res Psychiatry Brain Disord CRPBD-100006. Link: https://bit.ly/3gbRCto

43. Perrotta G (2020) The strategic clinical model in psychotherapy: theoretical and practical profiles. J Addi Adol Beh 3. Link: https://bit.ly/3n8Ecko

44. Perrotta G (2019) Paraphilic disorder: definition, contexts and clinical strategies. Journal of Addiction Neuro Research, Neuro Research 1: 4. Link: https://bit.ly/3q10IRV

Citation: Perrotta G (2021) Etiological factors and comorbidities associated with the "Gender Dysphoria": Definition, clinical contexts, differential diagnosis and clinical treatments. Int J Sex Reprod Health Care 4(1): 001-005. DOI: https://dx.doi.org/10.17352/ijsrhc.000018 
45. Perrotta G (2020) Sexual orientations: a critical review of psychological, clinical and neurobiological profiles. Clinical hypothesis of homosexual and bisexual positions. Int $\mathrm{J}$ Sex Reprod Health Care 3: 027-041. Link: http://bit.ly/2OaeUXv

46. Perrotta G (2020) Dysfunctional sexual behaviors: definition, clinical contexts, neurobiological profiles and treatments. Int J Sex Reprod Health Care 3: 061069. Link: http://bit.ly/3ryTgKU

47. Perrotta G (2020) Bisexuality: definition, humanistic profiles, neural correlates and clinical hypotheses. J Neuroscience and Neurological Surgery 6. Link: http://bit.ly/3uYoOHo

48. Perrotta G (2020) Cuckolding and Troilism: definitions, relational and clinical contexts, emotional and sexual aspects and neurobiological profiles. A complete review and investigation into the borderline forms of the relationship: Open Couples, Polygamy, Polyamory. Ann Psychiatry Treatm 4: 037-042. Link: http://bit.ly/3bl2zJ5

49. Perrotta G (2019) Depressive disorders: Definitions, contexts, differential diagnosis, neural correlates and clinical strategies. Peertechz Arch Depress Anxiety 5: 009-033. Link: http://bit.ly/3c3FAkR

50. Perrotta G (2019) Anxiety disorders: definitions, contexts, neural correlates and strategic therapy. J Neur Neurosci 6: 046. Link: https://bit.ly/3hGJwuf

51. Perrotta G (2019) Obsessive-Compulsive Disorder: definition, contexts, neural correlates and clinical strategies. Cientific Journal of Neurology 1: 08-16. Link: https://bit.ly/3hGJ5A7

52. Perrotta G (2019) Post-traumatic stress disorder: Definition, contexts, neural correlations and cognitive-behavioral therapy. J Pub Health Catalog 2: 40-47. Link: https://bit.ly/3ca8nUC
53. Perrotta G (2019) Neural correlates in eating disorders: Definition, contexts and clinical strategies. J Pub Health Catalog 2: 137-148. Link: http://bit.ly/3qoSCyi

54. Schwarz K, Fontanari AM, Mueller A, Soll B, da Silva DC, et al. (2016) Neura Correlates of Psychosis and Gender Dysphoria in an Adult Male. Arch Sex Behav 45: 761-765. Link: http://bit.ly/3kQD9pl

55. Karia S, Alure A, Dave T, Shah N, De Sousa A, et al. (2019) Paranoia in Patients With Gender Dysphoria: A Clinical Exploration. Indian J Psychiatry 61: 529-531. Link: http://bit.ly/3rncEe1

56. Perrotta G (2020) Borderline Personality Disorder: definition, differential diagnosis, clinical contexts and therapeutic approaches. Ann Psychiatry Treatm 4: 043-056. Link: http://bit.ly/3c5rsYi

57. Lingiardi V, Giovanardi G (2017) Challenges in Assessing Personality of Individuals With Gender Dysphoria With the SWAP-200. J Endocrinol Invest 40: 693-703. Link: http://bit.ly/3c3GvBP

58. Coates S, Person ES (1985) Extreme boyhood femininity: Isolated finding or pervasive disorder?. J Am Acad Child Psychiatry 24: 702-709. Link: http://bit.ly/38eB55D

59. Lingiardi V, Giovanardi G, Fortunato A, Nassisi V, Speranza AM, et al. (2017) Personality and Attachment in Transsexual Adults. Arch Sex Behav 46: 13131323. Link: http://bit.ly/38dF6Yj

60. Perrotta G (2020) "Perrotta Integrative Clinical Interview (PICl-1)" Psychodiagnostic evidence and clinical profiles in relation to the MMPI-II. Ann Psychiatry Treatm 4: 062-069. Link: https://bit.ly/3rqbgqX

\section{Discover a bigger Impact and Visibility of your article publication with}

\section{Peertechz Publications}

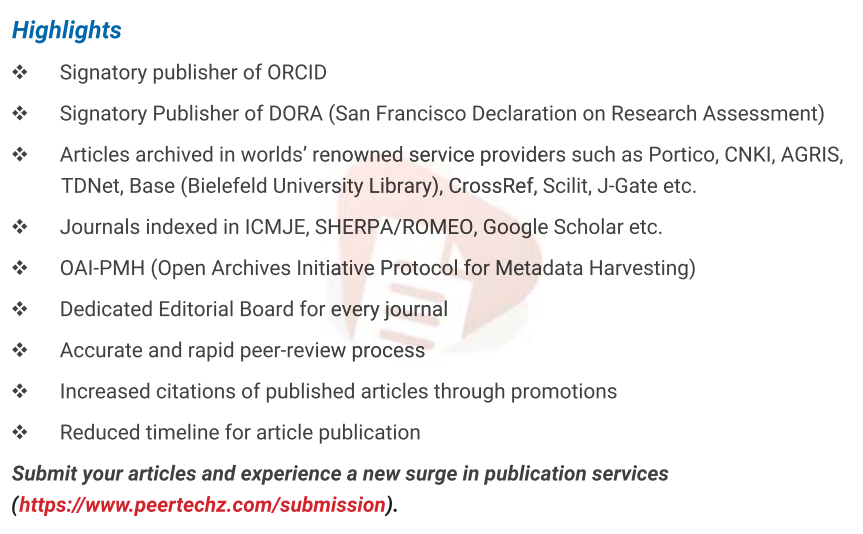

Peertechz journals wishes everlasting success in your every endeavours.

Copyright: (c) 2021 Perrotta G. This is an open-access article distributed under the terms of the Creative Commons Attribution License, which permits unrestricted use distribution, and reproduction in any medium, provided the original author and source are credited. 